УДК: 159.99

\title{
Интернет поведение детей младшего шкодьного возраста
}

\section{Маргарита И. Чумак*, Марина Ю. Елагина}

Донской государственный технический университет, г. Ростов-на-Дону, Российская Федерация

*E-mail: chumaaak1908@gmail.com

*ORCID ID: https://orcid.org/0000-0003-0468-262X

\section{Аннотация}

В статье представлены результаты исследования интернет повеАение Аетей м^аАшего школьного возраста. Рассмотрены возможные угрозы, причины и решение в случае алдиктивного поведения Аетей данной возрастной группы. Во Введении показана социальная значимость проблемы. Оценивается влияние Интернет пространства на становление мировоззрения и личностную структуру ребенка. Показаны возрастные особенности Аанной возрастной группы. Анализируются причины аААиктивного поведения. Новизна исслеАования заключается в преАСтав^ении краткого обзора исследований по проблеме Интернет поведения Аетей м^аАшего школьного возраста. В Теоретическом обосновании анализируется поведение м^аАших Школьников с прихолом технологизации и цифровизации. Выявлены причины «опасных» взаимоотношений с Интернетом. Рассматриваются возможные угрозы при использовании Интернет-ресурсов Аетьми м^алшего школьного возраста: контентные, коммуникационные, потребительские, технические, зависимости. Указаны источники возникновения данных угроз. Анализируется влияние и поведение младших школьников в Аанных ситуациях. Описываются залачи родителей Аля предотвращения Аанной проблемы и пример повеАения в случае возникновения проблемы. В ОбсужАении результатов поднимается вопрос обучения навыкам безопасного поведения в Интернет м^аАших школьников. Обосновывается необходимость разработки методических материалов по данной проблеме. Вылелены основные психолого-педагогические условия обучения млаАших школьников инфрормационной безопасности. В ЗакАючении отмечаются тенденции проблем обучения безопасного поведения Аетей млаАшего школьного возраста в Интернете. Отмечено, что начальная школа в наше время призывает к Аальнейшему изучению Аанного вопроса и необходимости разработки новых форм и методов обучения Аля повышения безопасности м^аАших школьников в сети. 
Innovative Science: psychology. pedagogy. defectology 2021 VOL. 4 \# 4

SOCIAL PSYCHOLOGY, POLITICAL AND ECONOMIC PSYCHOLOGY

\title{
КАючевые слова:
}

интернет поведение, м^алшие школьники, инфрормационная безопасность, психологическая безопасность, сеть, угрозы, интернет-срела, кибербул^инг, интернет-зависимость

\section{Для цитирования}

Чумак М. И., Елагина М. Ю. Интернет поведение детей младшего школьного возраста // Инновационная наука: психология, педагогика, дефектология. 2021. T. 4, No 4. C. 40-51. doi: https://doi.org/10.23947/2658-7165-2021-4-4-40-51

\section{Internet behavior of primary school children}

\author{
Margarita I. Chumak*, Marina Yu. Elagina
}

Don State Technical University, Rostov-on-Don, Russian Federation

*E-mail: chumaaak1908@gmail.com

*ORCID ID: https://orcid.org/0000-0003-0468-262X

\begin{abstract}
The article presents results of the study of primary school children Internet behavior. The possible threats, causes and solutions in the case of addictive behavior are considered. The Introduction shows the social significance of the problem. Internet space influence on the formation of the worldview and the impact on the personal structure of the child are evaluated. The age features of this age group are shown. The causes of addictive behavior are analyzed. The novelty of the study is to present a brief overview of studies on the problem of primary school children Internet behavior. The Theoretical justification analyzes the behavior of younger schoolchildren with the advent of technologization and digitalization. The causes of "dangerous" relationships with the Internet are revealed. Possible threats when using Internet resources by children of primary school age are considered: content, communication, consumer, technical, dependencies. The sources of these threats are indicated. The influence and behavior of younger schoolchildren in these situations is analyzed. This article describes the tasks of parents to prevent this problem and an example of behavior in the event of a problem. In the Discussion of the results, the issue of teaching the skills of safe behavior on the Internet to younger schoolchildren is raised. The necessity of developing methodological materials on this problem is justified. The main psychological and pedagogical conditions for teaching information security to younger schoolchildren are highlighted. In Conclusion, the trends of the problem of teaching safe behavior of primary school children on the Internet are noted. It is noted that the primary school in our time calls for further study of this issue and the need to develop new forms and methods of teaching to improve the safety of younger students in the network.
\end{abstract}


Инновационная наука: психология. педагогика. дефектология 2021 TОМ 4 № 4

СОЩИАЯЬНАЯПСИХОЯОГИЯ,ПОЛИТИЧЕСКАЯИЭКОНОМИЧЕСКАЯПСИХОЛОГИЯ

\section{Keywords}

internet behavior, primary school students, information security, psychological security, network, threats, internet environment, cyberbullying, internet addiction

\section{For citation}

Chumak M. I., Elagina M. Yu. Internet behavior of primary school children. Innovative Science: psychology, pedagogy, defectology, 4(4), 40-51. doi: https://doi. org/10.23947/2658-7165-2021-4-4-40-51

\section{Введение}

В настоящее время Интернет прочно закрепился в жизни человечества, в том числе и подрастающего поколения. Основной проблемой является активное использование Интернет пространства детьми младшего школьного возраста. Данный фактор влияет на становление мировоззрения, что оказывает сильное воздействие на дичностную структуру ребенка.

На сегодняшний день Интернет-среда перестала быть искдючительно сервисом поиска, хранения и передачи информации. Она вошла практически во все сферы жизни человека. Виртуальная среда входит не только в сферы коммуникации, но и затрагивает области деятельности становления дичности ребенка. Это вдияет на формирование интересов детей, что может привести к тому, что приобретенные посредством Интернета интересы не будут связанны с познавательной деятельностью, а полученные знания, зачатую, не несут пользы (Бабаева, Войскунский, 1998).

На данный момент не существует единого мнения о вдиянии Интернетсреды на детей. Некоторые исследоватеди считают, что пребывание детей в Интернете относится к аддиктивному поведению. При этом другие полагают, что Интернет-среда явдяется одной из видов жизненного пространства, где дети могут самовыразиться.

В наше время виртуализация жизни стала массовой за счет использования Интернета и гаджетов большей частью населения. Повседневность с каждым годом все больше набирает обороты в технологизации и цифровизации. Исходя из этого, встает потребность одновременно находиться в двух социальных средах материальной и информационной реальностях. Информационное пространство расширяется и исподьзуется не только для общения и развлечения, но и для рабочей и учебной сферы, что, в свою очередь, становится частью жизни. В силу системной цифровизации у детей младшего школьного возраста появляется необходимость в исподьзовании Интернет-среды.

Исходя из вышесказанного, дети являются активными подьзователями Интернет-среды. Ее исподьзование закдючается не только в обучении и поиске 
необходимой информации. Все больше детей младшего школьного возраста приобретают навык общения в сети.

Гаджеты и Интернет стали неотъемлемой частью современного мира. В связи с этим, перед родителями встает ряд вопросов о том, как уследить с кем и как общается ребенок в сети. Проблема закдючается в том, что зачастую дети не осознают риски, с которыми могут столкнуться в сети, не воспринимают советы родителей по данному вопросу, так как они разговаривают с ними не на их языке (Sparks, 1986). Перед родителями и педагогами образовательных организаций встает задача обеспечить безопасное пребывание ребенка в Интернете, научить его ориентироваться в сети и грамотно пользоваться Интернет-ресурсами.

Еще одной проблемой цифровизации человечества является «опасные» взаимоотношения с Интернетом и гаджетами. Они приводят к переносу внимания из реального в виртуальный мир, нарушая общественные связи. Данная проблема, зачастую, приводит к изменению мировоззрения (Кондрашкин, Хломов, 2012). Интернет как источник информации и способ отвлечься и отдохнуть не несет никаких угроз, но, когда его исподьзование не ограниченно, реальность в сети становиться более привлекательной, чем окружающая реальность. В таком случае можно говорить о зависимости от Интернет-среды. Дети младшего школьного возраста являются одними из первых в группе риска, так как пока не обладают достаточным самоконтролем и защитными психическими механизмами. Сеть создает илдюзию отсутствия ответственности за счет возможности остаться анонимным (Баранов, 2017). В связи с этим у детей можно заметить откдонения в поведении: мошенничество, обман, просмотр сайтов с порнографией, просмотр видео со сценами насидия, посещение групп в социальных сетях, призывающих к суициду и т.д.

На фоне быстрого распространения пандемии коронавирусного заболевания (COVID-19) стояла необходимость организации дистанционного образования. Помимо трудностей с предоставлением технологий для подключения и усвоения учебного материала возникла проблема самосознания школьника. До пандемии отделение школьной жизни от семьи, разделение роли ребенка для его родителей и роли ученика для учителей в школе решали данную проблему. В данном случае родитель выполняет роль как родителя, так и учителя, что мешает родителю замечать и признавать изменения, которые происходят в ребенке. Переход на дистанционное обучение измения процесс обучения из «живого» в виртуальный, в связи с чем количество проведенного времени за гаджетами заметно увеличилось. Во всем мире установлена единая норма прибывания ребенка перед дисплеем - 3 часа. Однако уместить организацию учебного процесса и дальнейшее пребывание в сети в эти временные ограничения во время пандемии так и не удалось ни одной стране (Нечаева, 2021). 


\section{Теоретическое обоснование}

Альтернативные персонажи, создаваемые детьми в Интернете, позволяют уйти от реального мира с его проблемами и сложностями, что в свою очередь является угрозой для целостности и идентичности личности. В случае, когда пребывать в сети ребенку намного комфортнее чем в реальности, возникает угроза десоциализации и не достижения успеха в реальной жизни. Выделяют следующий ряд угроз для психологической безопасности во время пребывания в сети детьми:

1. Контентные (порнография, сцены насилия, пропаганда вредных привычек, опасные диеты, призывы к суициду).

2. Коммуникационные (кибербуллинг).

3. Потребительские (неограниченное использование Интернет-магазинов, покупка низкокачественных товаров, потеря персональных данных и денег при заказе товаров онлайн).

4. Технические (вредоносные программы, потеря персональных данных, вздом аккаунтов).

5. Зависимости (потеря контродя в Интернете, замена реальности на сеть).

Рассматривая проблему контентных угроз в ходе международного исследования при помощи модуля «Родительский контродь» и исследований на базе динии помощи «Дети онлайн» были выявлены классификации запрещенных для детей сайтов по частоте посещаемости (Солдатова, Рассказова, Зотова, Пебешева, Роггендорф, 2012):

1. Сайты, несущие порнографический контент.

2. Сайты, содержащие сцены насидия.

3. Сайты, содержащие информацию об оружии и его продаже.

4. Сайты, содержащие информацию об алкоголе и наркотических веществах.

5. Сайты, позволяющие играть в азартные игры.

На данный момент к этому списку можно добавить Интернет-ресурсы, призывающие к суициду и рискованному поведению, так называемые «группы смерти».

Исходя из вышесказанного, отмечается необходимость в повышении компетентности использования Интернет-ресурсов детьми, а также разработка программных обеспечений позволяющих фильтровать контент.

Отдельно стоит отметить контент, создаваемый детьми младшего школьного возраста. На данный момент информационной площадкой для указанного возраста является приложение «TikTok». Отсутствие осознания того, что «все, что попадает в интернет, остается там навсегда» и илдюзия безнаказанности приводит к тому, что посты и видео, опубликованные младшими школьниками, довольно часто содержат нецензурную лексику. В данной проблеме родители не всегда могут выступать в качестве примера поведения в сети, так как и сами не осознают, что 
из себя представляет Интернет-среда. Для предотвращения данной проблемы необходимо не только использовать родительский контроль и фильтры, а также проводить родительские собрания и классные часы на тему контента в интернете.

В образовательных организация остро стоит проблема буллинга. Это объясняется тем, что школа является средой, позволяющей ребенку отвлечься от проблем, а также между учениками строятся ролевые взаимоотношения, включая «лидер-изгой». Булдинг представляет собой раздичные формы физических или психических притеснений (например: насмешки, прозвища, отражающие какие-либо особенности ребенка, порча личных вещей, вымогательство, издевательства и т. д.). В связи с цифровизацией данная проблема стала иметь свое распространение и в сети. Новые технологии позволяют расширить ряд возможностей для булдинга, и дети активно пользуются этим. Современные дети подвергаться булдингу в сети так же часто, как и в реальной жизни. По данным исследования «Дети России онлайн» было выявлено, что в среднем $23 \%$ детей подвергались кибербулдингу. Кибербуллинг заключается в оскорблениях в беседах в социадьных сетях, в комментариях под постами и видеородиками, так же отмечаются более серьезные случаи, такие как вздом личных страниц, размещение ложной информации о человеке, размещение постов с оскорбительными комментариями (Sourander et all., 2010). Каждый десятый ребенок становиться жертвой кибербулдинга. Особенно серьезно переживают булдинг дети младшего школьного возраста. Чаще всего жертвами становятся девочки. Было отмечено, что кибербулдинг приводит таких детей к сильному или очень сильному разочарованию (Бочавер, Хломов, 2013). В ходе исследований упомянутых выше было выявлено, что агрессоры в реальной жизни зачастую не признают, что прибегают так же к кибербулдингу. Выделяются основные черты детей подверженных булдингу (Макарова, Макарова, Махрина, 2016):

- проблемы с физическим развитием;

- неуверенность в себе;

- тревожность;

- пугливость;

- застенчивость;

- замкнутость;

- чувствительность;

- склонность к депрессии.

В связи с этим встает вопрос предотвращения или уменьшения негативных последствий кибербулдинга. Необходимо объяснять детям, что читать оскорбления также обидно, как и слышать, поэтому следует общаться в Интернете дружелюбно. Необходимо научить ребенка правильно реагировать на оскорбления в сети, рассказать ему, что не стоит отвечать агрессору агрессией, а если проблема не решается, лучшим решением будет уйти с данного ресурса, удадив 
личную информацию. Аучший способ избежания булдинга - игнорирование оскорблений (Зинцова, 2014).

Еще одним изменением в поведении детей с развитием цифровизации стадо возникновение потребительских отношений среди детей. Если раньше под данным понятием подразумевалось использование товаров, приобретённых родителями, то сейчас дети зачастую вовлечены в процессы потребления. То есть дети не только принимают решение о приобретении того или иного товара, но и могут самостоятельно приобретать необходимые им товары.

С каждым годом объем карманных денег детей растет. В связи с доступностью Интернет-магазинов, и благодаря наличию карманных денег, количество детей среди пользователей данных сервисов также растет. Исходя из вышесказанного можно сделать вывод, что дети являются одними из потребителей Интернетмагазинов. Проблема заключается в том, что, не владея достаточными самоконтролем и защитными психическими механизмами, дети вступают в группу диц подверженным мошеннической деятельности. В основном мошенники исподьзуют следующие психологические приемы:

1. Очень выгодное предложение.

2. Психологическое давление и заявление об ограниченности товара иди ограниченном времени его продажи.

3. Выдача себя за другого человека.

Дия предотвращения потребительских рисков родителям стоит придерживаться следующих правил:

1. Проверять сайты, на которых ребенок хочет совершить покупку.

2. Проводить беседы о мошенничестве в Интернет-ресурсах.

3. Контродировать электронные средства платежей.

Одним из главных правил предотвращения данной угрозы является демонстрация в качестве примера своего поведения в Интернет-магазинах.

Технические угрозы касаются не только детей, но и их родителей. При предоставлении своего гаджета ребенку возникает риск потери персонадыных данных.

Зачастую дети в сети ищут бесплатное популярное программное обеспечение, музыку, картинки, видео и игры. Киберпреступники активно пользуются этим фактом. В силу недостаточного владения защитными психическими механизмами, дети доверяют всем ссылкам и вдожениям, при переходе по которым можно не только потерять персонадьные данные, но и поставить под угрозу всю локальную сеть.

Для предотвращения данной проблемы необходимо говорить с детьми о безопасности в Интернете, объяснять, что не все приложения могут быть бесплатными. Нужно говорить о необходимости спрашивания совета у родителя о переходе на сайт, если ребенок не уверен в его безопасности. Так же нужно установить защитные разрешения, блокирующие небезопасные ссылки 
и проверяющие программные обеспечения на наличие вредоносных файлов.

Увлеченность Интернетом детьми младшего школьного возраста может привести не только к проблемам со здоровьем, но также и к Интернет-зависимости. У ребенка данного возраста зависимость от сети развивается гораздо быстрее, чем у взрослого человека (Widyanto, 2006). Понятие «Интернет-зависимость» было введено в 1995 психиатром Иваном Голдбергом, который рассматривал ее как психическую зависимость.

Основной причиной Интернет-зависимости младших школьников является возможность получения раздичных форм социального признания (Белинская, 2009). В данном возрасте происходит изменение всего уклада жизни в связи с переходом от игрового вида деятельности к учебному. С началом школьной жизни у ребенка меняются ценности, интересы и статус, возникают вопросы связанные с поиском места в коллективе, все это приводит к эмоциональной напряженности. Дети данной возрастной группы интенсивно развиваются практически во всех сферах (например: развитие психических процессов, увеиичение знаний, физический рост). Зачастую такая эмоциональная напряженность приводит к конфликтам в семье, в коллективе или в кругу друзей. Самым простым и самым распространённым на сегодняшний день способом ухода от выше указанных проблем младшим школьником является виртуальная сеть (Оськина, 2012). Для предотвращения формирования Интернет-зависимости у ребенка необходимо систематично проводить профилактические работы со школьниками и их родителями. Задача родителей определить первые признаки, помочь не «увязнуть» ребенку в сети и предпринять необходимые меры. Выделяют два признака Интернет-зависимости:

1. Физиологический: утомляемость, мышечная слабость, ухудшение зрения, мигрени, пренебрежение гигиеной, отсутствие сна.

2. Психодогические: раздражительность, агрессия при отвлечении от сети, скрытность, апатия при отсутствии доступа к сети, эмоционадьная неустойчивость, необычный эмоционадьный подъем при использовании Интернет-пространства, отсутствие интереса к вещам, не связанным с Интернетом.

Так же стоит отметить следующие изменения в жизни ребенка: ухудшение успеваемости, изменение в поведении, сужение контактов с друзьями, «уход» в себя, бесконтрольное использование гаджетов и Интернет-пространства. Для предотвращения подобных изменений для детей младшего школьного возраста стоит установить временные рамки использования Интернета, ненавязчиво следить за Интернет-ресурсами и играми, используемые ребёнком, и пытаться переключать внимание на интересные ему виды деятельности.

Помимо интернет-зависимости, так же стоит вопрос о зависимости от компьютерных игр. Среди популярных игр у детей младшего школьного возраста 
отмечают «Among Us», «Minecraft», «Roblox». Зачастую младший школьник в свое свободное время может довольно долго исподьзовать гаджет для игры, при этом его подожение не всегда комфортно и удобно, что приводит к негативному вдиянию на здоровье. Из-за длительного провождения времени за играми могут возникать: утомляемость глаз, мигрени, боли в спине и т. д. Длительное пребывание в игре влияет на психическое здоровье: у детей младшего школьного возраста это выражается в повышенной возбудимости и отсутствии навыков общения. Перед многими родителями стоит проблема не в количестве потраченных часов на игру, а в самих играх, в которые играют дети. Одной из самых популярных игр среди младших школьников на сегодняшний день является «Among Us». Многие родители обеспокоены задачей, стоящей перед игроками «найти предателя», подразумевая, что это развивает жестокость. Но если рассмотреть игру «Мафия» можно сделать вывод, что задачи в ней и рассматриваемой выше игре схожи, но не представлены в графическом виде. Нередко родитеди просто не понимают видеоигры, а с непониманием приходит и страх. В конце концов, не столько сама игра наносит вред ребенку, сколько само количество времени, проведенное за игрой. Для решения данной проблемы необходимо с ранних лет налаживать контакт с ребенком, общаться с ним на равных, интересоваться его увлечениями и стараться поддерживать их.

\section{Обсуждение резудьтатов}

С каждым годом все сильнее заметна тенденция временного переноса: если раньше вопросы поднятые выше можно быдо отнести искдючительно к средним школьникам, то на сегодняшний день вышесказанное напрямую относится и к младшим школьникам. Исходя из этого проблема информационной безопасности и корректного Интернет поведения детей младшего школьного возраста является особенно актуальной. Повышение психологической и физической защищенности ребенка в условиях технологизации и цифровизации можно считать одной из нынешних передовых проблем. В связи с этим обучение навыкам безопасного поведения в Интернете младших шкодьников имеет большую значимость. Данная проблема актуальна для таких отраслей науки как педагогика и психодогия.

Методическим аспектам современных подходов к проблеме безопасности младших школьников в сети уделяется недостаточно внимания. В первую очередь, это недостаточная осведомленность родителей в вопросах информационной грамотности и безопасного поведения в сети. Профилактикой данной проблемы среди детей младшего школьного возраста не занимаются должным образом.

Идея «гуманизации современной системы образования» подразумевает доступность необходимой информации для младших школьнико, поэтому возникает потребность защиты от «опасной» информации (Фельдштейн, 2010). 
Основными психодого-педагогическими условиями обучения младших школьников информационной безопасности являются:

- Подготовка индивидуадьных и групповых занятий для работы с детьми младшего школьного возраста посвященных Интернет-среде.

- Семинары и кругдые столы на тему Интернет-безопасности детей с родителями.

Обучение информационной безопасности должно иметь модульную форму, а во время проведения занятий с младшими школьниками должны использоваться современные средства обучения (Букина, 2014). Стоит отметить необходимость проведения профилактических работ по данной теме.

\section{Закдючение}

Проблема Интернет поведения младших школьников возникает из-за недостаточного внимания к данной теме со стороны образовательных организаций и родителей. Отметим существующие проблемы в обучении безопасному поведению детей младшего школьного возраста в Интернете:

1. Недостаточное рассмотрение проблемы развития навыков безопасного поведения в сети исследователями.

2. Обучение информационной грамотности - один из главных аспектов профилактики информационных угроз.

3. Создание информационно-просветительских работ для детей младшего школьного возраста и их родителей.

Отметим, что начальная школа в наше время призывает к дальнейшему изучению данного вопроса и необходимости разработки новых форм и методов обучения для повышения безопасности миадших школьников в сети.

\section{Авторы заявляют об отсутствии конфликтов интересов.}

\section{Дитература}

Бабаева, Ю. Д., Войскунский, А. Е. (1998). Психологические последствия информатизации. Психологический журнал, 19(1), 89-100.

Баранов, Е. Г. (2017). Информационно-психологическое воздействие: сущность и психодогическое содержание. Нациинальный психологический журнал, 1(25), 25-31. doi: https://doi.org/10.11621/npj.2017.0103

Белинская, Е. П. (2009). Взаимосвязь Интернет-зависимости и стратегий совладания с трудными жизненными ситуациями. В А. Е. Войскунский (ред.) Интернет-зависимость: психологическая природа и динамика развития. Сборник научных трудов (С. 48-62). М.: Акрополь.

Бочавер, А. А., Хломов, К. Д. (2013). Булдинг как объект исследований и культурный феномен. Психология. Журнал Высшей школь экономики, 10(3), 149-159. 
Букина, Е. Ю. (2014). Формирование у младших школьников навыков безопасной работы в сети Интернет. Информатика в школе, 5(98), 40-49.

Зинцова, А. С. (2014). Социальная профилактика кибербуллинга. Вестник Нижегородского университета им. Н. И. Аобачевского. Серия: Соцчиальные науки, 3(35), 122-128.

Кондрашкин, А. В., Хиомов, К. Д. (2012). Девиантное поведение подростков и Интернет: изменение социальной ситуации. Психология. Журнал Высшей школь экономики, 9(3), 102-113.

Макарова, Е. А., Макарова, Е. А., Махрина, Е. А. (2016). Психологические особенности кибербулдинга как формы интернет-преступления. Российский психологический журнал, 13(3), 293-311. doi: https://doi.org/10.21702/rpj.2016.3.17

Нечаева, А. Ю. (2021). Влияние пандемии и дистанционного обучения на психическое состояние детей младшего школьного возраста. Скиф. Вопросы студенческой науки, 5(57), 75-78.

Оськина, Н. Г. (2012). Профилактика интернет-зависимости у младших школьников: новая модель. Начальная школа плюс до и после, 7, 17-20.

Солдатова, Г., Рассказова, Е., Зотова, Е., Дебешева, М., Роггендорф, П. (2012). Дети России онлайн. Результаты международного проекта EU Kids Online II в России. URL: http://detionline.com/assets/files/helpline/Final_Report_05-29-11. pdf (дата обращения: 22.07.2021).

Фельдштейн, Д. И. (2010). Изменяющийся ребенок в изменяющемся мире: психолого-педагогические проблемы новой школы. Нац̨иональный психологический журнал, 2, 6-11.

Sourander, A., Klomek, A. B., Ikonen, M., Lindroos, J., Luntamo, T., Koskeiainen, M., Ristkari, T., Helenius, H. (2010). Psychosocial risk factors associated with cyberbullying among adolescents: A population-based study. Archives of General Psychiatry, 67(7), 720-728. doi: https://doi.org/10.1001/archgenpsychiatry.2010.79

Sparks, G. G. (1986). Developmental differences in children's reports of fear induced by mass media. Child Study Journal, 16(1), 55-66.

Widyanto, L., Griffiths, M. (2006). 'Internet Addiction': A Critical Review. International Journal of Mental Health and Addiction, 4, 31-51. doi: https://doi. org/10.1007/s11469-006-9009-9

\section{References}

Babaeva, Yu. D., \& Voiskunsky, A. E. (1998). Psychological consequences of informatization. Psychological Journal, 19(1), 89-100. (in Russ.)

Baranov, E. G. (2017). Informational and psychological impact: the essence and psychological content. National Journal of Psychology, 1(25), 25-31. doi: https://doi. org/10.11621/npj.2017.0103 (in Russ.)

Belinskaya, E. P. (2009). The relationship between Internet addiction and coping 
strategies with difficult life situations. In A. E. Voiskunsky (ed.) Internet addiction: the psychological nature and dynamics of development. Collection of scientific papers (pp. 48-62). Moscow: Akropol'. (in Russ.)

Bochaver, A. A., \& Khlomov, K. D. (2013). Bullying as an object of research and a cultural phenomenon. Psychology. Journal of the Higher School of Economics, 10(3), 149-159. (in Russ.)

Bukina, E. Yu. (2014). Formation of skills of safe work in the Internet for younger schoolchildren. Computer Science at School, 5(98), 40-49. (in Russ.)

Feldstein, D. I. (2010). A changing child in a changing world: psychological and pedagogical problems of a new school. National Journal of Psychology, 2, 6-11. (in Russ.)

Kondrashkin, A. V., Khlomov, K. D. (2012). Deviant behavior of adolescents and the Internet: changing the social situation. Psychology. Journal of the Higher School of Economics, 9(3), 102-113. (in Russ.)

Makarova, E. A., Makarova, E. L., Mahrina, E. A. (2016). Psychological features of cyberbullying as a form of Internet crime. Russian Psychological Journal, 13(3), 293-311. doi: https://doi.org/10.21702/rpj.2016.3.17 (in Russ.)

Nechaeva, A. Yu. (2021). The impact of the pandemic and distance learning on the mental state of primary school children. Skiff. Questions of Student Science, 5(57), 75-78. (in Russ.)

Os'kina, N. G. (2012). Prevention of Internet addiction in primary school children: a new model. Elementary school plus before and after, 7, 17-20. (in Russ.)

Soldatova, G., Rasskazova, E., Zotova, E., Lebesheva, M., Roggendorf, P. (2012). Children of Russia online. The results of the international project EU Kids Online II in Russia. URL: http://detionline.com/assets/files/helpline/Final Report 05-29-11. pdf (accessed: 7/22/2021). (in Russ.)

Sourander, A., Klomek, A., Ikonen, M., Lindroos, J., Luntamo, T., Koskeiainen, M., Ristkari, T., \& Helenius, H. (2010) Psychosocial risk factors associated with cyberbullying among adolescents: A population-based study. Archives of General Psychiatry, 67(7), 720-728. doi: https://doi.org/10.1001/archgenpsychiatry.2010.79

Sparks, G. G. (1986). Developmental differences in children's reports of fear induced by mass media. Child Study Journal, 16(1), 55-66.

Widyanto, L., \& Griffiths, M. (2006). 'Internet Addiction': A Critical Review. International Journal of Mental Health and Addiction, 4, 31-51. doi: https://doi. org/10.1007/s11469-006-9009-9

Zintsova, A. S. (2014). Social prevention of cyberbullying. Vestnik of the Nizhny Novgorod University named after N. I. Lobachevsky. Series: Social sciencies, 3(35), 122-128. (in Russ.) 